\title{
DOES ANYBODY NEED ARCHITECTURAL THEORY ANY LONGER?
}

\author{
A B S T R A C T
}

My paper describes the grounds and the boundaries of theory, particularly of architectural theory. From the etimology of the word theoria to its definitions, one analyzes most of its implications, from "observed practice" to critical objects, i.e. built versions of current spatial concepts.

"Theoria suggests a perspective upon an extensive territory, from a significant distance (...)”

Richard Rorty ${ }^{1}$

Augustin Ioan

Ion Mincu University of Architecture and Urbanism - SITT Doctoral School
KEY WORDS

THEORIA

OBSERVED PRACTICE

PHILOSOPHY OF SPACE 
Architecture in theory and practice on the one hand, as well as philosophy of space on the other, shall be submitted to study in order to shape the present stage of mutual relations between those fields, thus allowing subsequent propositions of alternatives to the present state of affairs. Therefore, I shall comment on a few hypostases of the eye cast on things, in order to establish the precise type of contemplative consideration theory implied. Subsequently entering the territory of architecture, I shall try to determine its fortes as to acquiring knowledge related to architecture (the making, the optimization of the process, the recurrent feature of algorithms, the assuming of the tenets), so as to eventually get to set its limits in terms of experimenting and inventing. To conclude I will try to identify the (re)sources for a new transfiguration at the level of the interface between philosophy and architecture, this change having given grounds to expectations for almost a decade now, ever since the deconstruction has worn out its potential of informing on the architectural change.

\section{GAZE}

Seeing and being seen, in terms of spatiality, are the two visibility items generating the public site, for as long as this mutual examination (or its possibility) lasts. On the other hand, the visibility excess in the treatment of arts (particularly architecture, most relevant in this context), associated by certain researchers with the discovery of the perspective during Renaissance, has been severely exposed to criticism of theorists and philosophers of phenomenological descendant arts in the last few years. Language itself more numerous and in detailed terms associates the knowledge to the eyesight than to any other sense. The terms I propose here are: visibility (observation), to gaze, overseeing/surveillance and contemplation.

Visibility is to be treated in broader philosophical terms, as a human being's potential to introduce one's own self in relation to the others. Visibility implies a process (as it is not an immutable gift, but a temporary and fluctuant one), a context (as it is a relation between inner meaning and appearance, between the individual and the species, etc.); it ultimately is a pre-condition to being seen by the Other. Visibility is the obviousness of things. One can only see what is already visible ("always/already", as Heidegger once said), or that which becomes visible through a deliberate act of "clearing", of liberating; or, on the contrary, an act of occulting that which had been visible as a preliminary, precisely to render the space to what is wishfully brought to 
visibility (again). In order to complete this perspective, one must however acknowledge that the eyesight does not operate on a neutral field in its area of influence, but on the one that already stands out, since visible, unlike the rest. In other words, the gaze operates on what already stands out, yet invisible, although visible ${ }^{2}$ through the narrow disclosure of veils. Thus what we are dealing with here is a half-way encounter of the potential object of gaze and the actual one.

Science claims, not without reason, to have extended our capacity of examining things that place themselves to our potential gaze, through the optical technologies. Nowadays we can see in infra-red, in ultraviolet, through radar or sonar, or even through radio-telescopes. With the IT technologies we can now shape and thus bring to visibility geometrical figures otherwise unconceivable, like the fractals for instance, or we can draw the graphs of mathematical functions inviting to such visualization. Visual models, no matter how approximate and temporary they might be, render intelligible through visualization the structure of the small or of the big universe. By gazing, we assume reality.

However, in this visualization field, there are ways of singling out or focusing upon details of what we actually see, thus amplifying one thing's visibility as compared to the others, even on the very territory of visibility itself. ${ }^{3}$ But, since gaze and gazing became almost common terms in fine arts analysis, insisting on the meaning of these terms will undoubtedly prove its usefulness further in the economy of the text.

In The Concise Oxford Thesaurus -A Dictionary of Synonyms (Oxford: OUP, $1995,322)$ to gaze is defined as "stare, look fixedly, gape, goggle, stand agog, watch in wander, ogle, eye, take a good look, contemplate"; or "[to] look with curiosity or wonder, look intently" in The Oxford Dictionary of English Etymology (Oxford: OUP, 1966, reprint 1992, 392); or "[to] stare vacantly or curiously; now usu., look intently or fixedly (...) look fixedly at, stare at" in The New Shorter Oxford English Dictionary (Oxford: OUP, 1993, 1069). Gaze has gawk as a synonym, while the noun means "fixed look, intent, look, gape". The etymology of the word is unknown, but it is probably derived from the medieval gawe (cf. ODEE) or to gaw (cf. NSOED), which most likely explains its synonymy with gawk.

One must acknowledge that the definitions provided evidently differ significantly in the meanings they lay out. To look fixedly and vacantly might even imply absence of any intention of actually seeing, possibly denoting an 
instance of auto-hypnosis or of abstraction from any contingency, if not daydreaming. "Watch in wonder", another meaning provided, refers rather to the effect of what looking at something amazing has upon the one casting the look, and is more likely a definition of an "aggression" of the visible on the viewer. To see is a passive form under the circumstance: the viewer receives without actually choosing, falling a prey to the visibility of the world; while to gaze seems to suggest "an auctorial intent", directing the eye and using it as a tool in investigating the visibility offer: thus to gaze becomes in Romanian that "look intently" in the NSOED definition above quoted, or "take a good look" in the first definition, the one provided by COTDS.

Gaze is the agent of look here, insisting on the thing it fixes upon. The mutual exchange of intense looks between at least two human beings is an event which, once inscribed in space, leads to the metamorphosis of a place into a public site. The other manners of looking at things are evaluated as compared to it, and the diversity it institutes is disconcerting.

Surveillance, on the other hand, is an eye cast from a higher level, controlling the visibility field. This extraction from among the viewers who, by their crossing each other, sustain in terms of events the public site, this extraction from the horizontal mutual visibility field among humans is the first sign of establishment of a univocal relationship. The one looking around from among his peers does not have the overall perspective which surveillance provides. $\mathrm{He}$ is no different than his peers in terms of gazing and being gazed at. Even the private space he can gaze at is but a form of controlling nothing more than his own visibility: I allow the others to gaze at me or not. But the one casting the eye from a higher level (or from a privileged position, like for instance Bentham's panoptikon), controlling the others' visibility of his privileged viewing point, manages to get the whole picture but oversees the detail, the gaze-individuals. Having the possibility to survey (to see the whole picture, with or without being seen) is to Foucault the proof of the efficiency of punishment. Once the inequality is generated by the surveillance from a higher level spatially inscribed, it becomes a means of instituting and maintaining the social hierarchy, control, domination -the power, in one word.

Surveillance also means an excessive vigil, the meaning added to the one mentioned above, that of strength-giving. The light that was always lit in Stalin's Kremlin was the sign of such an exceeding vigil, of the perpetual surveillance of the public space that the power exerted: the individuals indulge in sleep, suspending the watch over themselves, while the power does not: its watching the others is ceaselessly ubiquitous. 
Contemplation is a form of casting an eye in abstraction of the contingent ("and the closed eye opens within", as said once by the Romanian poet Mihai Eminescu) where the inquisitive intention of the interrogative agent is missing; the contemplative life is the opposite of the active life. Contemplation is a special manner of looking at things -"view with attention" (ODEE, 208) which requires a detent-like space ("space for observation" in Ibidem) and moreover the temple which it actually holds within ("religious meditation" in Ibidem). Its compound word origin (con+templum) gives way to speculation regarding the analogy between contemplation and what ecclesia does in the sacred space. The act of being together in a temple - together with the temple - is a special type of gaze. The debate on the topic of the sacred space shall perhaps lighten somewhere else the mechanisms of this eye cast from the temple towards gods, through the intermediary of the sacred icons.

\section{THEORIA OR THE GAZE “FROM ABOVE”}

Theoria is an activity which, according to some researchers, has something to do with the gods, in its own turn (see Kagis McEwen), perhaps ascribing to spatiality a relationship with them. The theorist examines the object of its study (theory is "observed practice", as one of my teachers in Cincinnati used to say, although without any intent of commitment implied, on the contrary; lack of passion, of clenching and some detachment from the world are recommended to the theorist. Anyway, his friends, as well as his enemies, recommended to him to give up practice and confine himself to "philosophizing" on it. Theory thus becomes a buffer-space between the existing practice (the "observed" one) and the future one (therefore the "informed" one).

However the purpose of theory is not to substitute or undermine practice, on the contrary: to "cut out" and make public/accessible subroutines of making architecture as observed and quantified in existing works. But during this process, theory sets out on the idea -false, in my belief- that we can also explain and quantify other things besides the honest and decent professing of architecture. In Rorty's understanding of the term, theoria fails to grasp the detail, the texture of the surface it contemplates from high above and far away, and moreover, it looses touch with the reality it strives to describe and regulate afterwards. The issue of the theory of architecture is therefore that of proving to be, most of the times, a normative activity which, mediating between the (old) practice and the (new) practice and parasitizing on its active and committed feature, thus delays its experimental reflexes. Contemplation is a peripheral gaze, cast from above, and not at all committed, or at the very 
heart of events. Or this "limit" of theory being true, the following consequences are also true, as a result:

a theory is a must in teaching architecture as a practice average (a counterfeit of the long-ago abandoned activity of learning and acquiring a profession through a term of apprenticeship in some "master"s workshop). In other words, theory establishes and institutionalizes on a long term basis the "optimal" practices, those having a recurrence potential.

b_ Theory of architecture is useless in explaining or predicting vanguards or masterpieces, therefore having no determinative role in the renewal of the architectural language.

What might seem to be a handicap of theory, when thus formulated, does not make it less useful in the institutionalized study of architecture, like I said before, where the mistaken conception of theory as a false domain, a parasite of practice, still persists; theory acquires a "heroic" aura in the process, and being unable to explain one's own creation while in class (when it is valuable, or at least exists), or how a new one can be open to possibilities, this becomes the living proof that "art" itself can not be acquired through learning. It "is" an (al) chemical attribute of one's own genes (or worse, gonads). A certain rudimentary and naive feature as compared to the cultural aspects of the profession are thus celebrated and recommended to students in the name of the conservation of the "artistic sense" which might atrophy when too thoroughly cultivated. Those teaching theory courses are held in contempt as a group which is not allowed access to the "inspired" dimension of the profession and unsatisfied with their own existences, therefore being able to induce false necessities on students (reading of the "canonic" texts as well as of the last theoretical and philosophical news; historical study of one's own domain and of its nature and relation as compared to the other domains of art, culture, society). This group does nothing else but turns the student away from his ultimate goal, that one of "creating". It is not at all by fortuitous chance that the subjects relying on verbalized language when circulating information or interpretations on architecture are held in contempt in such an environment, as well as other activities like reading and writing -being exterior to architecture and therefore useless-, not to mention rhetoric (logic of argumentation, if not limpidity of a course actually being deliberately ignored, as "infiltrating agents" of theory). A "real" architecture professor does not talk or write, but draws. On the line, emphasizing the breach between the two languages is a distinctive sign among "board" architects, precisely because they do not cling to reading. 
In doing this, the partisans of teaching practice without any theoretical grounds throw in the abyss the very need for them in a university environment, out of an error of - horribile dictu! - logic. If it is true that the architectural "making" (i.e. the actual designing, which is but one of the infinitely branched aspects of architecture) can not be taught, then the workshops in an architecture school consistent to this perspective should be abandoned. Their place should be occupied by the apprenticeship in offices. Or few of the teachers supporting this "pure and harsh" perspective against theory ever thought of bearing the logical consequences of their own point of view: this would have meant for themselves to "theorize" and then set to practice the very consequences.

The "practice" schools I know about actually adopted an intermediate position: part of the time spent in school (fraction measurable in semesters, if not years) is devoted to "practice" in designing workshops and construction sites, at the end of the university studies or half-way through. Such an approach is meant to give the student the time to set some distance as to the knowledge acquired in the years past (which is critical, in a optimistic perspective), as well as to create at least a "reality effect", an appearance of immediate connection to current architectural activity implying routine and attrition.

As an intermediate area between social sciences and practice, the theory of architecture most obviously exceeds the boundaries of a definition of architecture centered on the evidence of already built structures only. It becomes an anthropology domain and allows information from the most various sources. On a "superior" level, information is provided by concepts borrowed from philosophy, esthetics and literature theory. In the "middle" area, by anthropology, various types of history, sociology, psychology (nowadays psychoanalysis, even furiously) and their derivatives and conjugates. In the "lower" area, by science, by technology suitable to its domain or not (although this distinction is difficult, in the context of the present fluctuations: the computers and, with it, the cyberspace and the VR have already become, or are about to become as peculiar to architecture as to building technologies). Obviously, there are secondary influences exerted on architecture theory which manage to penetrate the main flaw of (re)sources almost without any awareness on the side of those practicing theory (now that's an oxymoron!). One finds it hard to establish a direct relation between poetics courses and architecture theory, that is between poetry and architecture; still, they exist and have their own area of influence and practitioners of both (John Hejduk and Louis Kahn, for instance). 
Thus positioned, the theorists populate a no man's land by their contemplation, as a matter of fact, or, more precisely, they are "in the middle of nowhere". Philosophers hold in contempt the theorist's "contamination" of some ontological field beyond the thin air of philosophy itself, in absence of which it is impossible for the theorist to address the domain of which theory he practices. A philosopher can not be asked to "test" or try to prove a statement on some level other than the field of logical founding, as the French reaction to the accusations A. Sokal brought in his famous book; on the contrary he is entitled to borrow concepts from any other domain and (ab)use them under the shelter of allegory, metaphor or reinvesting with a meaning other than the one accepted in that domain. It is allowed to flatten the main sense of a concept strange to philosophy, but, on the contrary, it is forbidden to ask the philosophy to use such "recovered" concepts or make statements regarding that domain (science, language, anthropology, architecture, etc.). It would thus seem that there is no other relation between philosophy and the other ontological domains except a subordinating one. Therefore, philosophy of architecture could be but a pare-philosophy.

Moreover, the practitioners of that domain refuse its "citizenship" (although they sometimes reluctantly grant it a "transit visa" limited to the university environment, accusing it of not being really imbued with the "mysteries" of the profession, which only long-term practice, not contemplation or "philosophizing", can reveal. But on the other hand, the theory does not take any pleasure in the association with an activity that is so practice-"contaminated", therefore so deprived of "intellectuality" and "humanism".

\section{PHILOSOPHY $\leftrightarrow$ PRACTICE}

At some point on the interface between domains, an active minority is experimenting on the mutual transfer of information which should not be in need of any contemplative middle-person refusing its acting in the name of an intellectual superiority and of the supposedly privileged condition of the "spectator" of theory. This is also seen as "domestication" and transformation into tenet, if not vulgarization, of philosophical concepts. Or, just on the line, the ones interested to see if "testing" some concepts transferred from one domain into another proves to be fertile are the ones who actually work. What exactly is this domain boundary positioning? Briefly: avoiding of theory as a compulsory stage between existing and future practice on one side that is between strongly auto-reflexive architectural practice and philosophy (or in the case of sacred architecture, theology). 
These proceedings are not unknown to artists. In a minor form as compared to what is going on at the interface between philosophy and arts, the esthetics call it a turn to "unwontedness". Transferring from one domain to another, through the very gesture of changing context, produces something new and unexpected. This often occurs inside the very domain, when a concept or a method is old enough to be considered "out of fashion" or to have been simply forgotten.

Philosophy represents a privileged domain for architecture and vice versa, I dare say. In architecture, certain people - unable to choose between philosophy and practice - have decided to take both, abandoning the buffer area of theory. Bernard Cache, Cristopher Alexander, Daniel Libeskind or Peter Eisenman are practitioners and philosophers of architecture at the same time. On the other side, Heidegger uses space and location (not to mention the temple and the little house) as strong arguments in his philosophy; that, and the influences exerted by other phenomenologists already created a branch of contemporary philosophy called "critical regionalism" by the one who also drew up its "manifesto" (K. Frampton). Walter Benjamin's "Arcades Project”, recently published in English ${ }^{4}$, is a philosophical exploration of architecture in general ("dream houses", street-town, archways and passages), that is mainly of the $19^{\text {th }}$ century Parisian one. Derrida himself was brought to the point where he was actually committing himself to the architectural designing act (this exceptional cooperation between the philosopher and the architect is documented in Chora L Works by both Derrida and Eisenman).

Philosophers designing architecture? And why not? After all, others have done it before, without intending to or actually managing to set into practice the concepts of their own philosophy: Jung, Wittgenstein, Steiner. I'm not about to discuss here the results of this transgression of the boundaries between philosophy and the practice of architecture. I'm only acknowledging that nowadays, more than ever before, there is an almost violent immediacy in the relation between the two domains. This at least requires a research into the causes of this new attraction which makes philosophy and architecture reviews to publish together ${ }^{5}$, for instance, or some philosophers to draw chore on a given territory. Nowadays, some of the buildings produced by architects (alone or in a team with other experts, such as philosophers, or poets, or musicians) are explicitly designed to 
become objects of the philosophical inquiry as well. I confess my fascination for this alternative, the marginal way of being an architect, not only through reflexiveness towards one's own profession, but mainly through the most active commitment to its changing.

We also say what is opaque, but it is only because opacity is a form of visibility maintaining, however refusing access of the gaze "within".

I shall not go further, in spite of the almost Noica-like temptation to do it, speculating a subtle link between the excess of visibility/gaze and blindness, or between "blind" and "clear" which "to stare" might suggest; it probably is rather an analogy between the way in which the almost blind tries to distinguish things in the mist surrounding him: thus the one looking intently institutes a relation between the object of his exam and the rest, similar to the one between the barely-visible object and the almost invisible background in the retina of the "blind".

Walter Benjamin The Arcades Project (Cambridge, MA: Harvard University Press, 1999). See, for instance, the comments of T. J. Clark on the relation between the philosopher and the $19^{\text {th }}$ century Parisian architecture in the review he dedicates it in the London Review of Books, on the $22^{\text {nd }}$ of June, 2000, pp.3-9. on complexity published together with Architectural Design (Complexity-Architecture/Art/ Philosophy) by AD Academy Editions in 1995 is absolutely remarkable in terms of project and of substance. 